Int. J. Electrochem. Sci., 14 (2019) $9622-9632$

\title{
Low-cost and Highly Sensitive Sensor for Determining Atorvastatin Using PbTe Nanoparticles-Modified Graphite Screen-Printed Electrode
}

\author{
Ehsan Pourtaheri ${ }^{1,2, *}$, Mohammad Ali Taher ${ }^{1, *}$ Gomaa A.M. Ali ${ }^{3}$, Shilpi Agarwal ${ }^{4}$, \\ Vinod Kumar Gupta, ${ }^{4, *}$ \\ ${ }^{1}$ Department of Chemistry, Shahid Bahonar University of Kerman, P.O. Box 76175-133, Kerman, Iran \\ ${ }^{2}$ Young Researchers Society, Shahid Bahonar University of Kerman, P.O. Box 76175-133, Kerman, \\ Iran \\ ${ }^{3}$ Chemistry Department, Faculty of Science, Al-Azhar University, Assiut, 71524, Egypt \\ ${ }^{4}$ Center of Excellence for Advanced Materials Research, Faculty of Science, King Abdulaziz \\ University, Jeddah 21589, Saudi Arabia \\ *E-mail: e.pourtaheri94@gmail.com (E. Pourtaheri), ma taher@yaoo.com (M.A. Taher), \\ vinodfcy@gmail.com (V.K. Gupta).
}

doi: $10.20964 / 2019.10 .01$

Received: 18 June 2019 / Accepted: 29 July 2019 / Published: 30 August 2019

In this work, PbTe nanoparticles-modified graphite screen-printed electrodes (PbTe NPs/SPE) has been designed for electrochemical determination of atorvastatin for the first time. Striking advantages, including easiness, low manufacturing cost, and being one-use are exhibited by the sensor. Analyte electrochemical behavior was characterized by cyclic voltammetry. Electrochemical behavior of atorvastatin at $\mathrm{PbTe} \mathrm{NPs} / \mathrm{SPE}$ was also discussed. Additionally, quantitative detection of atorvastatin was done by differential pulse voltammetry. Under optimized conditions, the resulting signals were linearly inserted within an atorvastatin concentration range of 1-70 $\mu \mathrm{M}$. High diffusion coefficient of $3.7 \times 10-5 \mathrm{~cm}^{2} \mathrm{~s}^{-1}$ and low limit of detection of $0.05 \mu \mathrm{M}$ were obtained for atorvastatin detection using $\mathrm{PbTe} \mathrm{NPs} / \mathrm{SPE}$. Moreover, the usability of the PbTe NPs/SPE sensor by measuring atorvastatin in real samples was reported. The sensor offers greater accuracy, which implies its massive capacity for functional uses.

Keywords: Atorvastatin, PbTe nanoparticles, Electrochemical sensor, Graphite screen-printed electrode, Cyclic voltammetry. 
(C) 2019 The Authors. Published by ESG (www.electrochemsci.org). This article is an open access article distributed under the terms and conditions of the Creative Commons Attribution license (http://creativecommons.org/licenses/by/4.0/). 